\title{
UNCTAD's Investment Policy Reviews: Key policy lessons
}

\section{Chantal Dupasquier, Massimo Meloni and Stephen Young*}

Recognizing the potential of foreign direct investment (FDI) for development, the development community has sought measures to support developing countries to attract FDI and to maximize its benefits. In this context, the United Nations Conference on Trade and Development (UNCTAD) has developed its Investment Policy Review (IPR) programme to provide developing countries with recommendations for improving their business environment in order to better derive development gains from FDI. As a body of work, the IPR series has discerned common obstacles to FDI attraction among many developing countries. These include a lack of clear rules; ineffective policy implementation or follow-through; and FDI policies which do not reflect country-specific conditions, such as the level of development, the availability of infrastructure, skills and resource endowments. Drawing on a recently published report by UNCTAD, Investment Policy Reviews: Shaping Investment Policies around the World, this paper summarizes the lessons learnt from the programme and highlights issues and challenges for policy and corporate strategy on cross-border investment.

Key words: foreign direct investment, development, investment policies, regulations

JEL classifications: F21, F23, K20, G30, M16

\section{Introduction}

The United Nations Conference on Trade and Development (UNCTAD) launched its Investment Policy Review (IPR) programme in 1999 in response to a growing demand from developing countries for policy advice on FDI. Each IPR provides the country under review an independent and objective evaluation of the country's policy, regulatory and institutional environment for FDI, as well as customized recommendations to the Government for attracting and benefiting from flows of foreign direct investment (FDI).

Chantal Dupasquier and Massimo Meloni are UNCTAD staff. Stephen Young is Professor of International Business at the University of Glasgow, United Kingdom. 
Since the programme's inception, IPRs have been undertaken for over 30 countries around the world, covering least developed countries (LDCs), post-conflict countries, middle-income countries, as well as transition economies. The principle underpinning the IPR is to create preconditions for growth and poverty alleviation by promoting FDI and stimulating its interactions with the local private sector. The focus of the IPR is therefore to propose a series of reforms to the investment framework in recipient countries. Each IPR is systematically followed by implementation programmes in the subject country, for which UNCTAD cooperates intensively with other development partners to support the delivery of proposed solutions. ${ }^{1}$

The objective of this paper is to summarize the principal lessons for foreign investment policy and the role of FDI in the development process, based on the programme's experience. The paper draws on the recently published stocktaking report, Investment Policy Reviews: Shaping Investment Policies around the World, which reviews and synthesizes the challenges facing developing economies and the strategies recommended in the IPR series for attracting and benefiting from FDI. These lessons are also reflected in UNCTAD's Investment Policy Framework for Sustainable Development (UNCTAD 2012).

\section{Lessons from the Investment Policy Review Programme}

Through assessment of the investment climate in a range of developing countries, the IPR has identified a number of important lessons for investment policymaking and the development process. The IPR series shows that inward FDI and transnational corporations (TNCS) can play a significant role in, for example, meeting huge infrastructure needs, but the interactions between foreign investors and the local private sector are also vitally important. Attracting and benefiting from FDI, furthermore, places significant responsibility on host country governments in devising and implementing appropriate policies and regulations in areas such as human resource development, taxation and in creating effective institutions to ensure compliance and good

${ }^{1}$ For more details on the programme, its impact and country coverage, see www. unctad.org/ipr 
governance. Some major policy lessons that have emerged from the IPR series are highlighted in the remainder of this section.

\subsection{FDI policy needs to fully take local economic and social conditions into account.}

The level of economic development and the specific challenges facing countries naturally has a large bearing on required FDI policy responses.

For instance, for the poorest countries, the lack of basic infrastructure, skills and a robust policy framework presents major challenges in attracting FDI. Political instability - even violent conflicts - and health issues such as HIV/AIDS and malaria endemic may add to the problems.

Even for more advanced developing countries, inadequate infrastructure and skills availability often present challenges as they seek to move into higher value-added activities. However, these are of a different dimension, relating, for example, to the effects of infrastructure weaknesses (e.g. high telecommunications charges) on competitiveness, and to human resource issues such as rising labour costs, weaknesses in science, engineering and technology education, and perhaps a limited pool of skilled professionals.

Issues such as R\&D financing and attracting technology-based investment are more germane in advanced developing economies. Problems of weak governance tend to come into sharper focus in these countries (although problems of poor implementation of laws and corruption exist in many economies).

Challenges are different again in transition economies. The starting point for FDI policies for these countries has been the opening up and reforming of their economies for investors. Reforming large state-owned enterprises, often with a view to privatizing them at a later date, encouraging start-ups and fostering a culture of entrepreneurship have typically been central concerns.

Thus, even for the same objective of attracting FDI and maximizing its benefits, there are no universal policy prescriptions. Difference circumstances require different policy responses. In formulating FDI 
policy, policymakers therefore need to take into account the economic and social conditions of the country and ensure the compatibility of FDI policy with overall development strategy.

\subsection{Regional integration is gaining salience as a policy measure to attract FDI, especially in poorer countries}

Countries with small populations low income levels are at a disadvantage in attracting market-seeking FDI. Geographic factors such as being landlocked or sparsely populated often add to the difficulties. These disadvantageous conditions apply to most small island developing states (SIDS) and the majority of countries in Africa.

In this context, regional integration is becoming an important component in the arsenal for attracting FDI. Regional integration can enhance the attractiveness of member countries by increasing the potential market size from the investor perspective. Furthermore, regional integration is even more effective if the grouping, for instance, adopts a common regulatory framework or develops regional transport and communications networks.

To take a specific example, some of the regional agreements in Africa are beginning to evolve into genuine free trade areas with large market potential. For instance, the East African Community has created a market of 130 million people with a combined GDP of over $\$ 70$ billion.

Development partners are promoting regional integration as key part of their aid for trade programmes. The revised ACP-EU-Partnership Agreement, for example, is strongly promoting regional integration as a mechanism for fostering cooperation and peace and security, promoting growth, and tackling cross-border challenges.

TNCs are also adopting a regional approach in devising their strategies. IPRs, for countries in East and West Africa, have observed that of TNCs seeking to expand operations and develop integrated value chains, a significant number of them have followed a regional strategy. In North Africa, too, there are illustrative cases of foreign affiliates with regional export mandates and of regional product specialization, some as long ago as in 1999. 


\subsection{Infrastructure matters greatly, and remains a formidable challenge}

The standard of physical infrastructure is of paramount importance for the provision of services to consumers and for facilitating business activities. The quality of infrastructure is hence a major determinant of FDI attraction. Raising finance, providing the legal and regulatory framework, and undertaking projects present formidable challenges. There are no panaceas or quick fixes, but the IPR programme has drawn a number of lessons:

(i) Efforts to increase private sector involvement through publicprivate partnerships (PPPs) are important, with TNCs often having a principal role;

(ii) In LDCs and SIDs, donor support and public investment remain vital to the provision of basic infrastructure services;

(iii) Countries must develop a strong legal and regulatory framework, preferably prior to the entry of investors, and secure the capacity to facilitate and regulate projects;

(iv) Opportunities for smaller-scale initiatives, involving new players and appropriate technologies should be sought, including "impact investments" which explicitly incorporate social, environmental and developmental objectives into their business operations.

Recent data indicate that the share of private sector investment in telecommunications is as high as 62 per cent in Africa. In contrast, the private share of investment in transport and energy in Africa is only 11 per cent; and as little as 6 per cent in water and sanitation (McKinsey \& Co., 2011). It suggests a need for devising regulatory frameworks that permit sufficient returns for investors, but at the same time ensure access to basic services for vulnerable segments of society.

\subsection{Building human resources requires long- term commitment and innovative policies}

The availability and costs of semi-skilled and skilled labour are major determinants of FDI flows and their contribution to the host 
economy. Building human capital is a process requiring long-term commitment and large-scale investments in the educational system at all levels, including in vocational training.

The IPR series has identified human resources as a key development constraint in many developing countries. The solutions proposed focus on three issues: (i) reform and liberalization of labour laws; (ii) establishing work permits and residence systems specifically designed for the entry of foreign workers and skills upgrading; and (iii) investment in education, including at university level.

The issue of facilitating the entry of foreign workers is highly sensitive in many countries. Systems of allocation of work permits for foreigners are often rigid and restrictive, despite suffering from a shortage of skilled labour in a number of fields. The IPR series has developed detailed proposals for the employment of foreigners, encompassing skills audits, and work permits and skills transfer policies.

Public investment in university education is a common response to skills shortages in the higher income developing countries of Africa and Central America. The IPR series has, additionally, presented proposals for foreign investment in education, in particular the establishment of world-class business schools as joint ventures between leading global universities and local partners. Some IPRs have extended such proposals to develop a strategy for FDI in education, incorporating regulatory, policy and institutional measures. The proposed regulatory measures include removing barriers to FDI in education and strengthening quality controls on universities; while policy and institutional measures are concerned with, for example, promoting region-wide recognition of qualifications, and building bridges between universities and the private sector.

\subsection{Reform of the investment framework is a key precondition for both FDI attraction and private sector development}

A major contribution of the IPR series is practical advice for reforming and modernizing the investment framework in host countries. Required reforms range from a complete overhaul of the investment code and general policies to detailed business-related measures. These legal/regulatory reforms are of enormous value in providing a secure 
and stable environment for investors, as well as ensuring adequate protection of the public interest. The non-FDI specific aspects of the investment climate show how policy measures affecting all businesses (taxation, access to land etc.) have a strong impact on a country's FDI attractiveness. Generally, there have been moves towards greater uniformity in investment frameworks, under the influence, for example, of World Trade Organization (WTO) rules concerning non-discriminatory treatment.

Among a range of requirements identified in the IPR series are:

(i) Ensuring coherence between policy objectives, policy tools adopted and their implementation;

(ii) Avoiding an over-reliance on fiscal incentives and reforming uncompetitive tax regimes.

(iii) Enacting competition policy and creating or strengthening related institutions

(iv) Strengthening the legal framework for land rights and ownership to facilitate access to land and transfer of land titles.

(v) Exercising caution in signing up to international investment agreements and ensuring coherence between international commitments and domestic legislation so as to protect the country's policy space and avoid an undue rise in investor-State disputes.

(vi) Improving institutional effectiveness as a prerequisite for improving the investment climate

\subsection{Reform of fiscal regimes should focus on core principles}

With respect to the fiscal regime, the IPR series has focused on core principles of simplicity, predictability and the promotion of development goals, while ensuring adequate revenue streams to finance public expenditures.

The IPR series has often identified tax regimes and fiscal incentives which are: 
(i) Overly complex and hence lacking in transparency, thus imposing very high administrative costs both upon investors and tax authorities;

(ii) Unstable and unpredictable, leading to investor confusion and loss of confidence;

(iii) Attractive for investors, but may encourage tax engineering, arbitrage and evasion, discourage start-ups and fail to produce sufficient revenue to provide essential public services and address the social and economic needs of the majority of the population; and

(iv) Not sufficiently targeted to promoting specific development goals, including technological upgrading, job creation and cluster development.

In a number of countries, general corporate taxation has been high but then significantly reduced by incentives, where almost everyone benefited. In such cases, the first step of the reform is to put in place a competitive general regime and in so doing simplify the tax system and reduce the transaction costs to investors. A competitive corporate tax regime is provided for all businesses, with the flexibility to support specific measures targeted at, for example, innovation and value chain development.

This consideration of the tax regime leads to a further key lesson which concerns the role of export processing zones (EPZs) and free zones (FZs or multi-facility zones) in development. While many developing countries have established such zones in the past, they have been widely criticized for expensive fiscal and other incentives, including subsidized rent and services; bureaucratic policy frameworks; and, in some cases, for inadequate coordination between private developers and governments in zone provision.

Lessons from the experience of the IPR programme are:

(i) Zones need to be integrated with host economies as direct benefits are extremely limited when zones operate as enclaves;

(ii) Associated with the above, the distinction between zones and the rest of the economy for tax purposes should be removed; 
(iii) Zones should not be viewed as substitutes for a country's wider trade and investment activities;

(iv) The regulatory framework should provide streamlined procedures for business registration and operation;

(v) Private rather than public development of zones increases the likelihood of success; and the operation of zones should be undertaken by the private sector on a commercial basis;

Based on those lessons, general recommendations of the IPR programme include: (i) to change the profile of zones from EPZs to FZs with unlimited market access; (ii) to coordinate fiscal incentives inside and outside the zones; (iii) to adopt measures to encourage supplier development and linkages in target sectors in FZs; and (iv) to move to a greater role for the private sector in the development of zones.

The approach of the IPR programme is consistent with the WTO Agreement on Subsidies and Countervailing Measures, which prohibits incentives directly linked to export performance. This prohibition affects all the IPR countries in Central America; the final transition period for reforming FZ and maquila laws which are incompatible with WTO rules into general regimes ends in 2015.

\subsection{The local private sector is critical to improving the benefits of FDI}

An important aspect of investment framework reform is private sector development. The aim is to especially encourage local entrepreneurship and the development of small- and medium-sized enterprises (SME), with a view to enhancing absorptive capacity and facilitating linkages with and spillovers from FDI. Such programmes should promote five areas which enhance benefits gained through linkages, namely: (i) suppliers/buyers identification; (ii) transfers of technology; (iii) training, technical and managerial; (iv) information sharing in respect of technical requirements and future orders; and (v) financial support.

Linkages programmes have not always been successful, especially those established as part of government requirements through local content programmes in the 1970 s and 1980 s. Contemporary linkages programmes seek open, collaborative arrangements between willing 
partners, with long-term commitment from government and both foreign investors and local enterprises. There are still challenges from suppliers' ability to meet cost and quality standards, through them being able to supply in sufficient volumes to avoid production gaps among customer TNCs, to maintain stable relationships in areas such as pricing policies. However, stimulating a symbiotic relationship between TNCS and SMEs is crucial in the generation of dynamic economic benefits from FDI.

In several countries, there remains a philosophy of retaining a strong presence by State-owned enterprises (SOEs). The IPR recommendation, in these cases, was to move from a "steer and control" approach to a "regulate, enforce and monitor" policy stance. Thus steps were proposed to separate the ownership and regulatory functions of the State to ensure a level playing field between private companies and SOEs in commercial activities.

Elsewhere the challenge is to deal with poorly performing SOEs as part of a general governance issue. In such cases, SOEs need to be modernized to facilitate their effective participation in the provision of key infrastructure and social services. This is crucial as UNCTAD data show that, for example, the public sector still accounts for half of infrastructure investment in most developing countries.

Competition and regulatory issues also need to be considered. Telecommunications has often successfully attracted investment from a sufficient number of operators to render the industry competitive. However, in other industries such as water and energy, it is harder to introduce the same degree of competition in the industry. In such cases, there is a clear need for an effective regulatory regime to ensure that public monopolies are not replaced by private foreign monopolies, without the incentives and competitive pressures to invest in and improve services.

Countries may wish to retain a level of control over some infrastructure alongside foreign and other private investors. The need for a fair, transparent and effective regulation to ensure impartiality is all the more essential. 


\subsection{Effective institutions and implementation of laws matter greatly as part of improving public governance}

Governance comprises two components: the design and effectiveness of laws and regulations; and the performance of regulatory institutions in the implementation of these laws.

Among the extensive range of challenges associated with weak institutional performance and poor implementation of laws are: (i) design of the tax system and low rates of tax collection; (ii) weaknesses in the rule of law and in the performance of the courts and the judicial system; (iii) red tape and bureaucracy; and (iv) land issues and property rights. Competition policies are sometimes non-existent or inadequate to protect consumers; and corruption is associated with weak institutions. One recommendation emerging from the IPRs to promote good governance is to establish a regulatory commission or equivalent.

Although these are long-standing issues in the context of FDI, both agriculture and land issues are high on the FDI and development agenda again. The challenges stem from concerns over food security, climate change, inadequate energy supplies, structural policy failures, and problems of land tenure (UNCTAD, 2009 and 2010). Secure property rights are vital in allowing private enterprise to flourish. The substantial contribution that the IPR programme have made in promoting secure land access, ownership and transfers is likely to be increasingly directed to property rights for agricultural land in the coming years.

\subsection{An effective investment promotion agency is key for successful FDI attraction and facilitation}

Many IPRs conducted by UNCTAD tackle the weaknesses of investment promotion agencies (IPA) - structure, governance, targeting and promotion strategies. In some countries, these IPRs have been instrumental for the radical overhaul of investment promotion agencies.

One of the recurring themes in this respect is IPAs' relative lack of attention to aftercare activities, in respect, for example, of linkages programmes and foreign affiliate development. Given the evidence of 
the importance of reinvested earnings FDI flows, the lack of interest may well result in missed opportunities. However, tracking of investors, both potential and established, is not widely undertaken. Other lessons include the necessity of high quality professionals and continued funding to ensure the sustainability of investment promotion activities, which often take time to bear fruit.

With an increasing number of governments promoting the internationalization of domestic enterprises and a continued focus on the promotion of export-oriented FDI by IPAs, it may be useful to integrate investment and trade promotion activities in one agency (UNCTAD, 2009). A growing number of countries operate in this way, and future IPRs, at least in more advanced developing economies, are likely to address this important issue.

\subsection{FDI can play a significant role in the development process, but it is not a panacea}

Assisted by strategic recommendations made by IPRs and their implementation, FDI has a potentially significant role to play in countries' development process. Apart from direct benefits in terms of employment, capital and know-how, the desirable function of FDI, however, is to harness the capabilities of the host country to attract and benefit from TNC activities, and to unleash the potential of domestic enterprises for the benefit of all its citizens. Hence a central policy objective is to integrate foreign investors within the business and societal fabric of the host economy.

While affiliates of TNCs have a potentially catalytic role to play, government policies also have a key input into this process by stimulating local enterprise development (primarily private but potentially also SOEs). These enterprise development policies range from encouraging entrepreneurship and start-ups; through formulating supplier development and export strategies, and cluster programmes; to helping build absorptive capacity to facilitate knowledge transfer from the foreign-owned sector.

Local enterprise development policies may also have a positive impact on the FDI attraction process by showing that the country is supportive of and open for business. A thriving SME sector is deemed to be necessary both to benefit from and to attract FDI. 
The requirements for long-term sustainable development extend further to an all-inclusive, partnership approach which includes not only FDI and a flourishing private sector, but also official development assistance and good public governance. Donor-funded initiatives have been highly valuable in the implementation of IPRs; and have a major role to play alongside governments and foreign investors in PPPs in infrastructure.

These conditions required for FDI-led, self-sustaining growth are highly demanding. Attracting FDI itself is a difficult task, and achieving the benefits highlighted above can only be part of a longterm vision. FDI on its own is not a panacea for development, and what is required is an integrated approach to development involving the long-run commitment of all stakeholders. Host countries should be ambitious but must also be realistic in their aspirations for attracting and benefiting from FDI. The practical recommendations of the IPRs provide a platform for establishing the preconditions for private sector development (local and foreign), and building a robust local SME sector should be at least as high a policy priority as FDI attraction on the host country development agenda.

\section{Conclusion and the way forward}

The contribution of the IPRs lies in their practical, policyoriented and customized approach, and in their strong emphasis on implementation. Their success relies heavily upon commitment from the recipient country, and the sustained support of a high-level local champion. The experience of implementation is significantly positive. Support through UNCTAD technical assistance, often in collaboration with other development partners, can be crucial; although a number of recipient countries have undertaken implementation on their own or alongside donors. Progress with infrastructure developments continues to be challenging, whereas the reform and modernization of investment frameworks has been a major success.

What do the IPRs add to our knowledge concerning FDI and development? The evidence from the review of IPRs suggests that overhaul of investment frameworks can provide an important stimulus to the process of FDI attraction and to overall market reform. This has 
been not been addressed to any great extent in academic and policy studies to date. By contrast the IPR evidence supports the growing literature on institutions and institutional infrastructure as a key FDI determinant.

The attraction of FDI per se is not an end but one element of the development process. Thus even greater emphasis should be given to the mechanisms through which FDI provides a catalyst for private sector development, job creation and poverty alleviation, including individual value-chains. Essentially, this means both helping to build a dynamic and growing domestic private sector in collaboration with foreign investors; and involving TNCs (and indeed all stakeholders) more closely in initiatives which are directly development-focused. Similarly greater consideration should be given to sectoral initiatives in manufacturing and agriculture where there is potential for strong linkages with local SMEs and, therefore, for poverty reduction. One particular contribution of the IPRs has been their focus upon firm-level issues, and, as with the World Investment Report, to apply international business, management and development theories and evidence to FDI policies. One example of this concerns multinational affiliate development programmes, which go beyond conventional aftercare for inward investors.

The world has changed considerably since 1999 and is likely to change again in perhaps unprecedented and unexpected ways over the course of this decade. For the future, a number of emerging issues will pose new policy challenges. The growing importance of new sources of FDI - South-South FDI, the role of SOEs and sovereign wealth funds, the rise of new business models and economic sectors will require innovative strategies and policy approaches. Furthermore, non-equity modes of international production, such as international subcontracting, management contracts or various forms of concessional arrangements are becoming of key importance. There are also new concepts generating interest in ideas such as 'corporate societal responsibility' and 'shared value' (Porter and Kramer, 2011). All these issues require a better understanding and call for further research to improve the policymaking process in the area of investment and foster development. 


\section{References}

McKinsey \& Co (2011). Addressing Africa's Infrastructure Gap. Presentation by Amine Tazi-Riffi at UNCTAD, Investment, Enterprise and Development Commission, Third Session. 2 May, Geneva.

Porter, M.E. and M.A. Kramer, (2011). The big idea. Creating shared value. Harvard Business Review. January-February.

UNCTAD (2009). Promoting Investment and Trade: Practices and Issues. Investment Advisory Series, Series A, number 4. New York and Geneva.

UNCTAD (2010). Technology and Innovation Report 2010: Enhancing Food Security In Africa Through Science, Technology and Innovation. United Nations publication. Sales no.E.09.II.D.22. New York and Geneva.

UNCTAD (2011). Promoting Investment for Development: Best Practices in Strengthening Investment in Basic Infrastructure in Developing Countries - A summary of UNCTAD's Research on FDI in Infrastructure. TD/B/C.II/12. 2-6 May, Geneva.

UNCTAD (2012). The Investment Policy Reviews: Shaping Investment Policies around the World. UNCTAD/DIAE/PCB/2011/9. United Nations. Geneva and New York.

World Bank (2005).World Development Report 2005. A Better Investment Climate for Everyone. New York and Oxford University Press.

World Bank (2011). World Development Report 2011 - Conflict, Security and Development, Washington D.C. 
